\title{
Development and Axonal Outgrowth of Identified Motoneurons in the Zebrafish
}

\author{
Paul Z. Myers, Judith S. Eisen, and Monte Westerfield \\ The Institute of Neuroscience, University of Oregon, Eugene, Oregon 97403
}

\begin{abstract}
We have observed the development of live, fluorescently labeled motoneurons in the spinal cord of embryonic and larval zebrafish. There are 2 classes of motoneurons: primary and secondary. On each side of each spinal segment there are 3 individually identifiable primary motoneurons, named $\mathrm{CaP}, \mathrm{MiP}$, and RoP. The motoneurons of the embryo and larva are similar in morphology and projection pattern to those of the adult. During initial development, axons of primary motoneurons make cellspecific, divergent pathway choices and grow without error to targets appropriate for their adult functions. We observed no period of cell death, and except for one consistently observed case, there was no remodeling of peripheral arbors.

We have observed a consistent temporal sequence of axonal outgrowth within each spinal segment. The CaP motor axon is the first to leave the spinal cord, followed by the axons of the other primary motoneurons. The Mauthner growth cone enters the spinal cord after all the primary motoneurons of the trunk spinal cord have begun axonal outgrowth. Secondary motor growth cones appear only after the Mauthner growth cone has passed by. Our results suggest that this stereotyped temporal sequence of axonal outgrowth may play a role in defining the contacts between the Mauthner axon and the motoneurons; the behavior of growth cones in the periphery suggests that interactions with the environment, not timing, may determine pathfinding and peripheral connectivity of the motoneurons.
\end{abstract}

The adult nervous system is characterized by highly specific synaptic connections, although the origin of this specificity is unclear. Studies in the chick (Hollyday, 1980, 1983; LanceJones and Landmesser, 1981a; Landmesser, 1980) and bullfrog (Farel and Bemelmans, 1985) have shown that the axons of motoneurons follow stereotyped pathways and initially project to appropriate regions of the developing hindlimb. Furthermore, by manipulating the environment through which these axons grow, Lance-Jones and Landmesser (1980a, b, 1981b) have shown that limb motoneurons will reach their appropriate targets even if they have to follow abnormal routes, suggesting that motor axons are guided to their targets by cues in the local environment. In contrast, observations in Xenopus (Lamb, 1976), axolotl (McGrath and Bennett, 1979), and the forelimb of the chick (Pettigrew et al., 1979) have suggested that motoneurons initially project to more regions of the developing limb bud than

Received Oct. 22, 1985; revised Jan. 10, 1986; accepted Jan. 13, 1986.

We thank Eric Hanneman, Bruce Mendelson, and Bill Trevarrow for their contributions to some of the material presented in this paper. Special thanks to Bill Trevarrow for his generous gift of the $\mathrm{zn}-\mathrm{l}$ antibody and to Ruth Bremiller for the preparation of antibody-stained slides. We also thank Charles Kimmel and Walter Metcalfe for their assistance and discussion, and Rachel Warga, James McMurray, and Harrison Howard for technical assistance. Supported by NIH NS17963 and NS21132 and the Medical Research Foundation of Oregon. J.S.E. was a postdoctoral fellow of the Muscular Dystrophy Association.

Correspondence should be addressed to Paul Zachary Myers at the above address.

Copyright (c) 1986 Society for Neuroscience $0270-6474 / 86 / 082278-12 \$ 02.00 / 0$ they will ultimately innervate. The inappropriate projections are thought to be eliminated later in development by retraction of collateral sprouts (Pettigrew et al., 1979) or selective cell death (Lamb, 1976, 1977, 1979; McGrath and Bennett, 1979), although inappropriate projections in animals with displaced motoneurons are functional and persist through the period of normal motoneuronal cell death (Lance-Jones and Landmesser, 1981 b; Landmesser et al., 1983).

One complication of previous studies of vertebrate motoneuron development has been that interpretations are based on statistical arguments from observations of populations of cells. We have developed a new preparation that is advantageous for these studies because, as in insects (Ball et al., 1985), we can follow the development of individual, identified motoneurons while they innervate their target muscles.

In the zebrafish, individual primary motoneurons can be uniquely identified by the positions of their cell bodies within a spinal segment and by their peripheral arbors (Westerfield et al., 1986), and the entire process of axogenesis, pathfinding, and establishment of the early projections of these individually identified motoneurons can be watched directly in living embryos (Eisen et al., 1986). The observations described in the accompanying paper (Westerfield et al., 1986) demonstrated that, in the adult, these identified motoneurons specifically innervate cell-specific subsets of muscle fibers in their own segment with a remarkable degree of precision. In the present paper, we describe the initial outgrowth of these same motoneurons in the embryo and show that they unerringly project to regions of the segment appropriate for their adult functions. We also examine a variety of events during development of the embryo that may correlate with this early specification.

Some of these results have appeared previously in abstract form (Eisen et al., 1984, 1985).

\section{Materials and Methods}

Embryos and larvae of the zebrafish, Brachydanio rerio, were obtained from a laboratory colony maintained at $28.5^{\circ} \mathrm{C}$ under a $14 \mathrm{hr}$ light, $10 \mathrm{hr}$ dark cycle. The developmental age during cleavage was determined by the number of cells (blastomeres) present in the animal. At later stages, the chronological age (in hours of age) was used as an approximate measure of the degree of development of an animal. Using the morphological criteria for staging animals of Hisaoka and Battle (1958), we have found that the embryos from any single day are essentially synchronous in their development; embryos fertilized on different days can vary by approximately $5 \%$ (or $1 \mathrm{hr}$ at $24 \mathrm{hr}$ of age) in their rate of development. Our observations were confined to segments 5-15 of animals that ranged in age from $17 \mathrm{hr}$ to $14 \mathrm{~d}$.

\section{HRP labeling}

The morphology of larval motoneurons was determined by labeling them with HRP applied to lesions of peripheral nerves in the living animal and later staining the fixed and sectioned 
tissue. The HRP-labeled material described in this work was prepared with methods used previously (Myers, 1985). Gross lesions of the axial muscles of larval zebrafish (aged 3-14 d after fertilization) were made with a glass needle or steel pin, and the wounds washed with a $7 \%$ solution of HRP in distilled water. After $30 \mathrm{~min}$ to $24 \mathrm{hr}$, the animals were killed and fixed in aldehydes and sectioned on a vibratome (see Myers, 1985). HRP was histochemically localized in the sectioned tissue either by a modified Hanker-Yates technique or after heavy-metal intensification (Kimmel and Law, 1985). All quantitative measurements made on fixed tissue were corrected for $20 \%$ shrinkage.

\section{Birthdays}

The time of origin of spinal motoneurons was determined by ${ }^{3} \mathrm{H}$-thymidine ( ${ }^{3} \mathrm{H}$-TdR) autoradiography and HRP histochemistry as described by Mendelson (1985). Approximately $5 \mathrm{nl}$ of ${ }^{3} \mathrm{H}-\mathrm{TdR}$ was injected into the yolk sacs of embryos between 9 and $25 \mathrm{hr}$ of age. The animals were allowed to survive until they were 4-5 d old, at which time they were processed for HRP histochemistry as described above. We confined this part of the study to those motoneurons that innervate the ventral muscles. The sectioned and stained tissue was re-embedded in EponAraldite and cut in $4 \mu \mathrm{m}$ serial sections. These sections were mounted on slides, coated with Kodak NTB2 emulsion, and developed in Kodak D-19 developer after exposure times of 4 7 weeks. We then used the HRP-staining to identify spinal motoneurons unambiguously and scored the cells for the uptake of ${ }^{3} \mathrm{H}-\mathrm{TdR}$ by the presence of silver grains. All the birthday results described in this report were obtained from such "doubly labeled" motoneurons.

\section{Nomarski microscopy}

We observed the initial outgrowth of motor growth cones in live, unlabeled embryos by means of Nomarski optics. Individual embryos were dechorionated and mounted between two coverslips separated by $300 \mu \mathrm{m}$ spacers. Embryos older than 19 $\mathrm{hr}$ that had begun to twitch were anesthetized in a dilute solution of tricaine-methanesulfonate (MS222; Sigma). All observations were performed in a room warmed to approximately $28.5^{\circ} \mathrm{C}$, using a Zeiss Universal microscope with Nomarski optics and a water-immersion objective with either $25 \times$ (na: 0.9 ) or $40 \times$ (na: 0.75) magnification.

\section{Injection of fluorescent dyes}

Individual blastomeres of blastulae at the 32- to ca. 1000-cell stage were injected with fluorescent dyes, and the resultant clones of labeled cells were assayed for the presence of motoneurons at 16-24 hr, using techniques developed by Kimmel and Law (1985). We injected 1-4 blastomeres into each of 1814 animals with either fluorescein or rhodamine isothiocyanate, conjugated to dextran to prevent diffusion of the dye between coupled cells. Sixty-nine percent of the animals injected survived the procedure; 87 animals ( $7 \%$ of the survivors) had fluorescently labeled clones that contained 1 or more motoneurons. Animals with labeled motoneurons had an average of $5 \pm 4$ segments containing labeled motoneurons. The animals were further selected for their suitability for observation; we favored small clones of brightly labeled, well-isolated cells so that (1) there was no ambiguity in following individual growth cones and axons, and (2) there was a minimum of extraneously labeled tissue, such as skin and muscle, to obscure our observations. The quantitative data presented in this paper were taken from observations of 30 animals that fit these criteria. These animals had a total of 92 labeled primary motoneurons and 80 labeled clusters of secondary motoneurons. Observations were made on a Zeiss Universal or UEM microscope with epifluorescence illumination using Zeiss filters for fluorescein or rhodamine. Neutral density filters were used to reduce the incident illumination to levels that minimized dye-sensitized photodamage (Miller and Selverston, 1979) and bleaching of the dyes. A silicon-intensifiedtarget (SIT, GE S7) camera (Kater and Hadley, 1982) was used to amplify the fluorescence to visible levels and transmit the image to a video cassette recorder and monitor. In several experiments, we used a VAX $11 / 750$ (DEC) minicomputer and video image processor (IIS) to enhance contrast.

\section{Results}

\section{Organization of developing motoneurons}

\section{Motoneuron classes}

Two distinct classes of spinal motoneurons, primary and secondary, are present in larval and embryonic zebrafish (Myers, 1985). Primary and secondary motoneurons can be distinguished by a number of morphological criteria, including soma shape, position, and size and axon diameter and path (Fig. 1). Although the cells express sufficient variation that the populations of primary and secondary motoneurons demonstrate some overlap in each of these criteria, the constellation of criteria available assured that individual motoneurons could be classified unambiguously.

Larval primary motoneurons have large somata $-11.3 \pm 1.4$ $\mu \mathrm{m}$ diameter (Fig. 2)-located relatively dorsally, above the ventral third of the spinal cord. Their axons are also relatively large (approximately $2 \mu \mathrm{m}$ diameter) and follow a ventral and medial path within the spinal cord, looping about the medial aspect of the Mauthner axon before exiting at the ventral root (Myers, 1985). Secondary motoneurons have smaller $(6.7 \pm 1.0$ $\mu \mathrm{m}$ diameter), rounder somata and are typically found in the ventral third of the spinal cord. Their axons are finer (less than $0.5 \mu \mathrm{m}$ diameter) and pass ventrally and laterally of the Mauthner axon to the ventral root.

In the embryo, primary motoneurons were recognized with Nomarski optics or after labeling with fluorescent dyes by their position and large somata even before they began to grow axons. Although they were sometimes confused with large spinal interneurons that occupy a similar position within the cord, any ambiguity was dispelled once the axon had grown more than a few micrometers. The primary motoneurons in the embryo are only slightly smaller than primary motoneurons in the larva (Fig. 2).

Primary motoneuronal somata in the embryo are first observed lying in a ventral location. As the primary motor axons elongate, the cell bodies simultaneously move dorsally at approximately $0.7 \mu \mathrm{m} / \mathrm{hr}$ between 18 and $36 \mathrm{hr}$ (Fig. $3 A$ ). By the time the animals are $2 \mathrm{~d}$ old, the primary motoneurons are in the dorsolateral position typical of larval motoneurons-Fig. 3 (Myers, 1985). The dorsal movement of the primary motoneuron somata occurs relative to other labeled cells in the spinal cord, including interneurons, secondary motoneurons (Fig. $3 B$ ), and Rohon-Beard cells, and thus probably represents migration.

\section{Individually identifiable primary motoneurons}

Within each segment, we have been able to identify uniquely individual primary motoneurons on the basis of the longitudinal positions of their somata and their peripheral arbors. These motoneurons correspond in position and morphology to the primary motoneurons identified in adult zebrafish (Westerfield et al., 1986). The application of HRP to lesions confined to the dorsal musculature typically labels no more than 1 primary motoneuron per segment (Fig. $4 A$ ) that is displaced a short distance rostrally from the ventral root (Fig. 5). HRP applied to unilateral lesions of the ventral musculature typically labels no more than 2 primary motoneurons in each segment (Fig. $4 B$ ). The more caudal and more consistently labeled of these 2 motoneurons is found within 1 soma diameter of the ventral root; we have named it $\mathrm{CaP}$ (caudal primary). The more rostral 

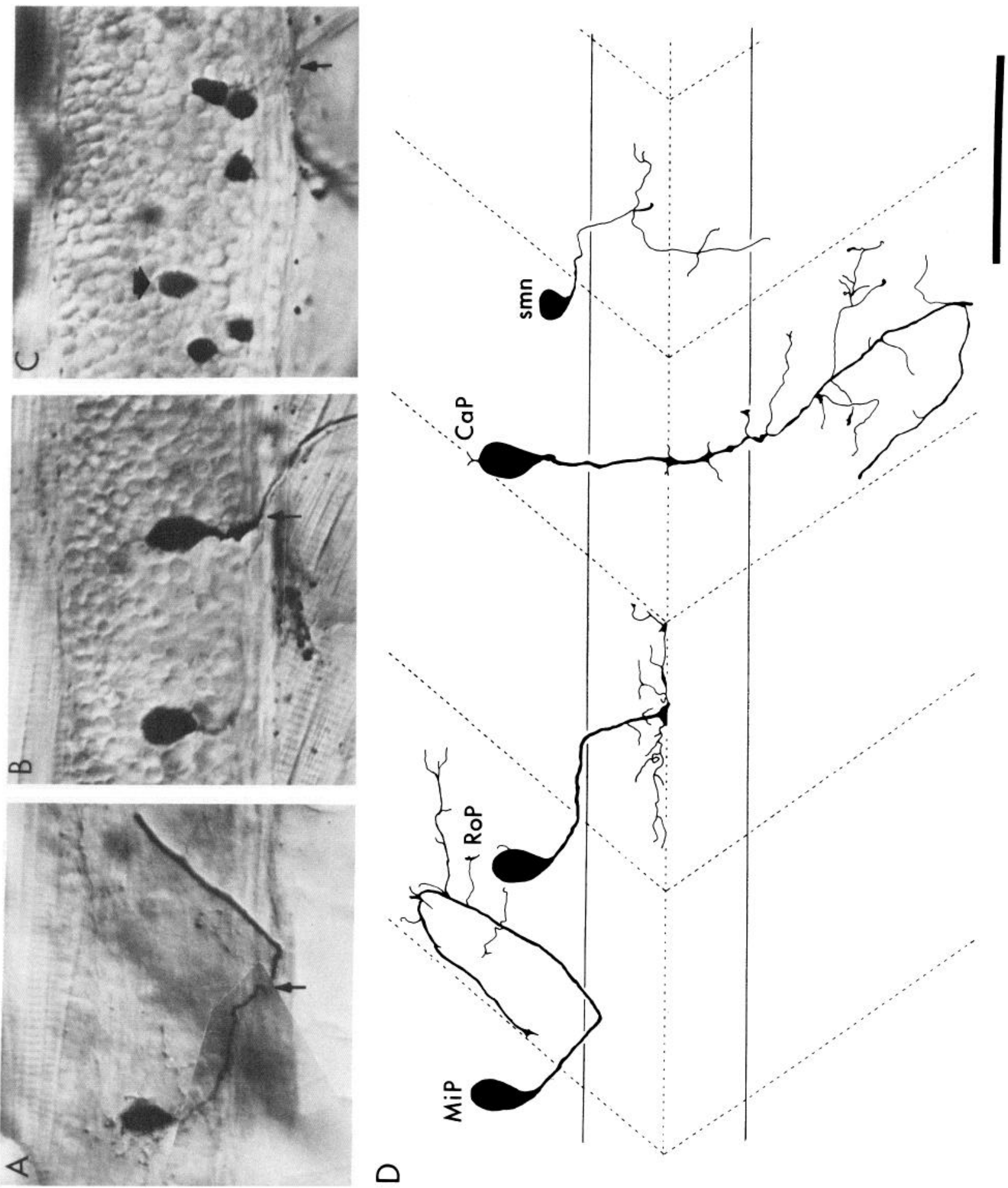

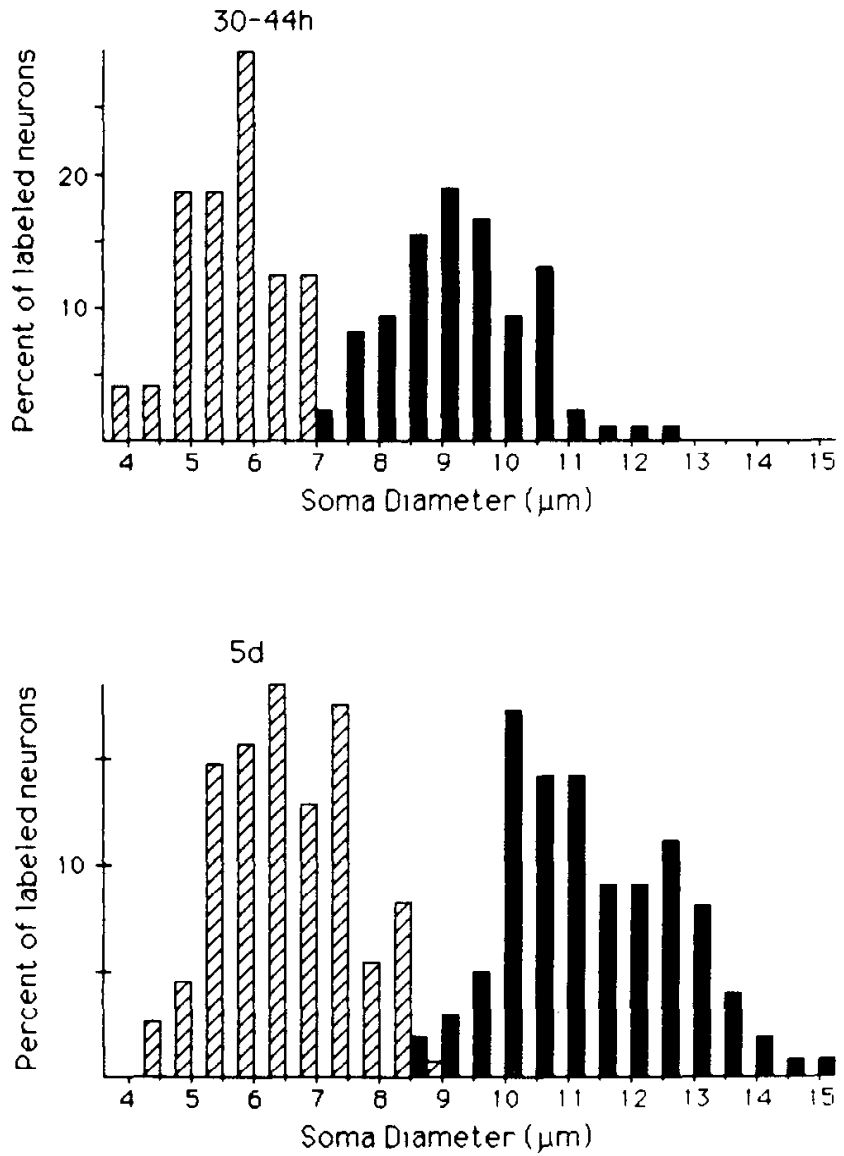

Figure 2. Primary motoneurons are larger than secondary motoneurons. The percentage of motoneurons of a given diameter is plotted for primary and secondary motoneurons of 30-44 $\mathrm{hr}$ (top) and $5 \mathrm{~d}$ (bottom) animals. In both histograms, primary motoneurons are represented by the solid dark bars, and secondary motoneurons by hatched bars. Top, Thirty to $44 \mathrm{hr}$ postfertilization. All cells were measured from taped video recordings of the live cells. Eighty-five primary motoneurons with a mean diameter of $9.9 \mu \mathrm{m}$ and 48 secondary motoneurons with a mean diameter of $5.8 \mu \mathrm{m}$ were measured. Bottom, Five days postfertilization. All measurements were made from fixed, HRP-labeled tissue. One hundred primary motoneurons with a mean diameter of $11.3 \mu \mathrm{m}$ and 110 secondary motoneurons with a mean diameter of $6.7 \mu \mathrm{m}$ were measured.

motoneuron that innervates the ventral musculature has been named RoP (rostral primary). The soma of the cell that innervates the dorsal muscles is found between those of the $\mathrm{CaP}$ and RoP motoneurons, and the cell has been named MiP (middle primary).

A similar, but compressed, distribution of 3 primary motoneurons in each segment was also found in the embryo (Fig. 5). As can be seen in Figure 5, the three primary motoneurons of the $24 \mathrm{hr}$ embryo are contained in a region within the segment that is approximately $30 \mu \mathrm{m}$ long; at this age, the segments of
Table 1. Motoneuron birthdays

\begin{tabular}{ccl} 
Age $^{a}$ & $\begin{array}{l}\text { Primary } \\
\text { motoneurons }^{b}\end{array}$ & $\begin{array}{l}\text { Secondary } \\
\text { motoneurons }^{b}\end{array}$ \\
\hline 9 & $100(7)$ & $100(4)$ \\
10 & $63(8)$ & $100(7)$ \\
11 & $70(10)$ & $100(8)$ \\
12 & $50(8)$ & $100(7)$ \\
14 & $20(5)$ & $100(4)$ \\
15 & $33(3)$ & \\
16 & $0(1)$ & $66(3)$ \\
19 & $0(2)$ & $50(2)$ \\
25 & $0(2)$ & $25(8)$
\end{tabular}

${ }^{a}$ Hours after fertilization.

${ }^{b}$ Percentage of cells that incorporated ${ }^{3} \mathrm{H}$-thymidine. Total number of cells observed is in parentheses.

the embryo are roughly $50 \mu \mathrm{m}$ long. The neurons of the spinal cord move longitudinally as the embryo develops. By day 5 , the segments of the larva have increased in length to roughly 100 $\mu \mathrm{m}$, and the primary motoneurons of a given segment are distributed over a region that is approximately $80 \mu \mathrm{m}$ long.

\section{Axonal arbors of primary motoneurons}

Peripherally, primary motoneuron arbors are confined to a single myotomal segment. In only a single case $(n=84)$ did we see a branch from a primary motoneuron cross a myoseptal boundary into an inappropriate segment. Centrally, no rostrocaudal overlap in soma position is observed between the motoneurons that innervate a particular segment and those that innervate adjacent segments. The motoneurons of a particular segment can therefore be studied independently of those of other segments.

Each of the 3 identified primary motoneurons has a characteristic, cell-specific peripheral arbor. The axon of the CaP motoneuron extends ventrally from the ventral root, within the space between the notochord and the medial surface of the axial muscles (Figs. 1, 6). Below the notochord, the axon extends within the ventral median septum to the ventral edge of the axial muscles, where it turns dorsally and laterally to project over the lateral surface of the axial muscles.

The axon of the RoP motoneuron courses ventrally with the axon of the $\mathrm{CaP}$ motoneuron on emerging from the ventral root. At the horizontal septum, however, the RoP axon turns laterally to extend within the horizontal septum to the lateral surface of the muscle (Fig. 1).

In the larva, the axon of the dorsal motoneuron, MiP, diverges immediately from the axons of RoP and $\mathrm{CaP}$ at the ventral root. The axon turns caudally and dorsally, coursing between the surface of the spinal cord and the medial surface of the axial muscles to the dorsal median septum. The MiP axon then extends dorsally to the surface of the muscle, where it turns to arborize ventrally over the lateral surface of the axial muscle (Fig. 1).

Figure 1. Primary and secondary motoneurons have different soma sizes, positions, and morphologies. $A-C$, Micrographs of motoneurons in sagittal sections of 5-d-old larvae stained for HRP. $D$, Composite drawing of fluorescently labeled neurons from several embryos after approximately $2 \mathrm{~d}$ of development. Scale bar, $50 \mu \mathrm{m}$. $A$, MiP motoneuron. This cell was labeled with HRP applied to a lesion of the dorsal muscles. The location of the ventral root is marked by an arrow in this figure, and in $B$ and $C . B, \operatorname{RoP}$ (left) and CaP (right) motoneurons. Both cells were labeled with HRP applied to a lesion of the ventral muscles. The axons of both motoneurons could be traced as far ventrally as the horizontal septum. $C$, Secondary motoneurons. A faintly stained primary motoneuron (RoP) is also present (large arrow). These cells were also labeled with HRP applied to the ventral muscles. $D$, Representative primary and secondary motoneurons at approximately $2 \mathrm{~d}$. All drawings are in the sagittal plane, with rostral at left; the solid horizontal lines drawn below the cells mark the outline of the notochord; the dotted horizontal line marks the location of the horizontal septum, and the dotted diagonal lines mark the boundary of the myosepta. 

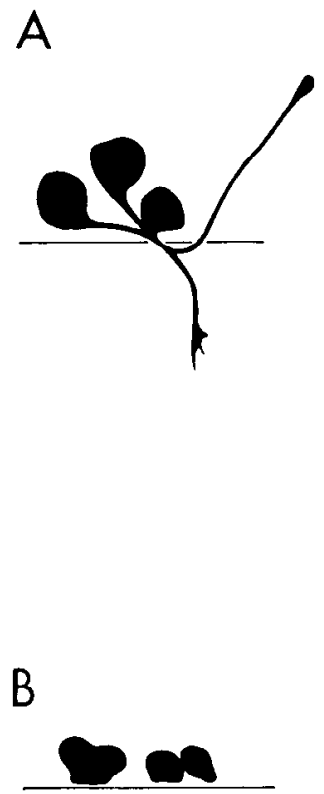
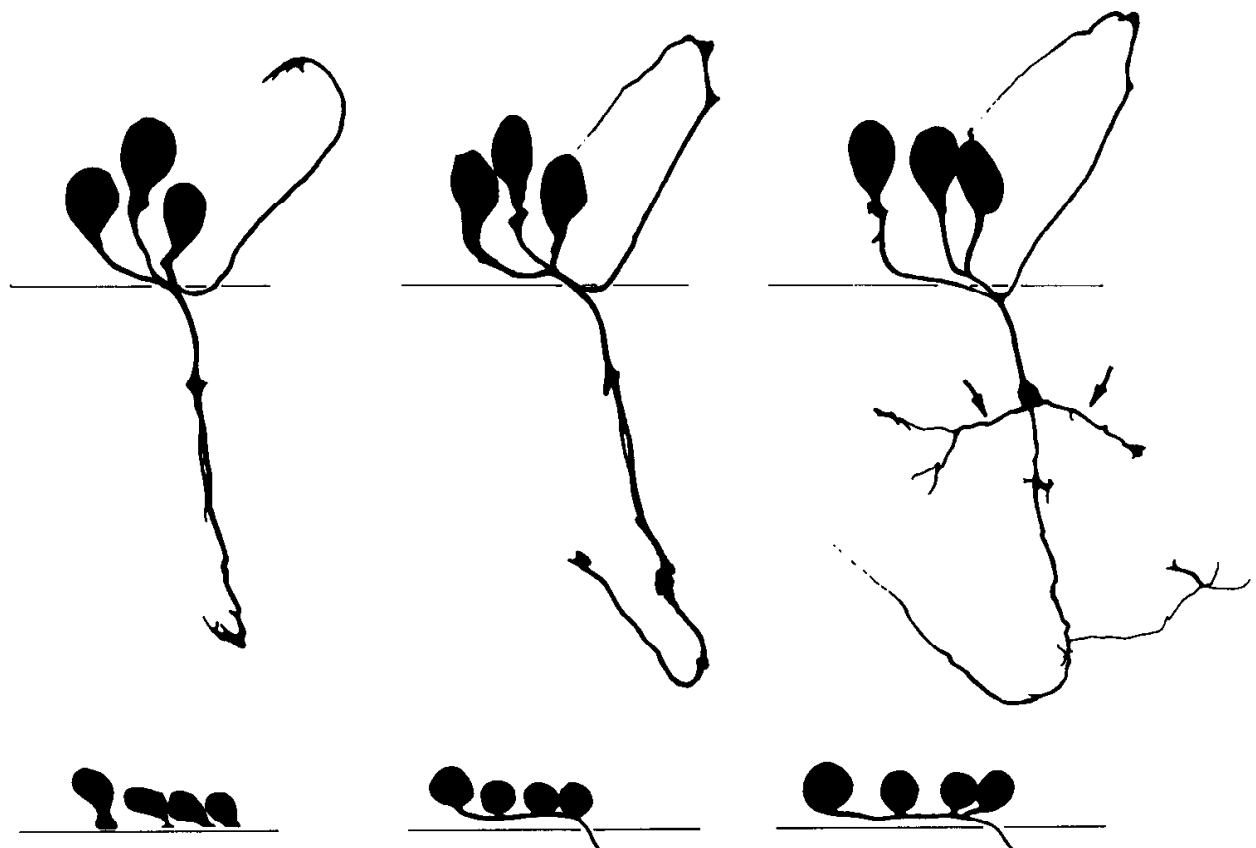

22.5

AGE (hours)
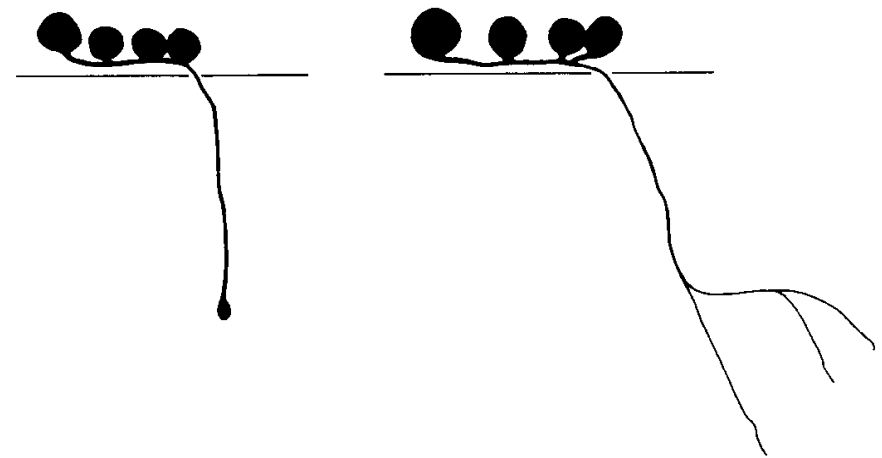

27

43

Figure 3. Development of fluorescently labeled primary and secondary motoneurons. These motoneurons were all located in the ninth segment of a single animal. The 3 primary motoneurons $(A)$ were on the opposite side of the cord from the cluster of secondary motoneurons $(B)$. The axons of the individual cells mingled too closely at the ventral root to allow them to be traced back to their cell bodies. It was clear that 2 axons were present in the ventral bundle of primary motor axons, and we would predict that the lateral branches in the horizontal septum (arrows) are from the axon of the RoP motoneuron (see Fig. 1). As in this case, it was rarely possible to distinguish individual secondary motor axons in the periphery, making it difficult to assess the rate of secondary motor axon outgrowth. Scale, $50 \mu \mathrm{m}$.

These results demonstrate the remarkably precise organization of the spinal cord in the young zebrafish and are consistent with studies in the adult (Westerfield et al., 1986). The two motoneuron classes, the primary and secondary motoneurons, are morphologically distinct. The motoneurons of each segment confine their arbors to the muscles of a single segment. Each primary motoneuron is individually identifiable, and its axon projects to a stereotyped, cell-specific region of the axial musculature. To elucidate the underlying developmental precision of this organization, we determined when the specific differences between primary and secondary motoneurons, and between individual primary motoneurons, are established.

\section{Motoneuron birthdays}

Primary and secondary motoneurons are born at different times. All primary motoneurons have undergone their final round of DNA synthesis between 9 and $16 \mathrm{hr}$ (Table 1). The first secondary motoneurons were born 5-6 hr after the first primary motoneurons, and new secondary motoneurons continued to be born until some undetermined time after $25 \mathrm{hr}$. No predictable sequence of primary motoneuron birthdays could be detected at any age. Individual cases were observed in which primary motoneurons in caudal segments were born before more rostral primary motoneurons. We cannot, however, rule out the possibility that more rostral populations of motoneurons tend to be born earlier than more caudal populations.

We could distinguish no consistent difference in the birthdays of the CaP and RoP motoneurons. Either motoneuron type, $\mathrm{CaP}$ or RoP, could be born first within a segment. Again, however, the data are insufficient to reveal any statistical trends for one cell type to be born before another.

\section{Axogenesis and the onset of functional interactions with axial muscles}

The first axons to grow out of the spinal cord are from primary motoneurons. Moreover, the first peripheral growth cone in any given segment invariably emerged from the $\mathrm{CaP}$ motoneuron, based on Nomarski observations of individual sements ( 38 segments, 4 animals).

$\mathrm{CaP}$ motoneurons sprout growth cones during a relatively short period beginning as early as $18 \mathrm{hr}$, the average age being $19.8 \pm 1.3 \mathrm{hr}$ (based on 33 fluorescently labeled primary mo- 
A

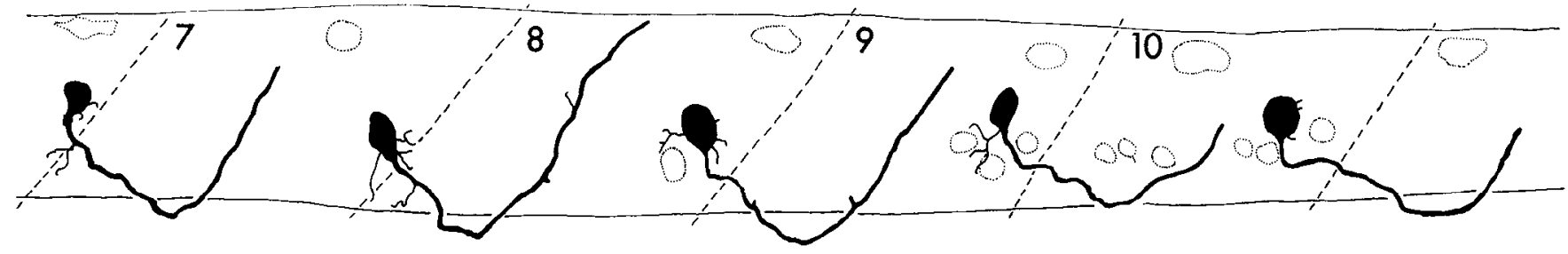

B

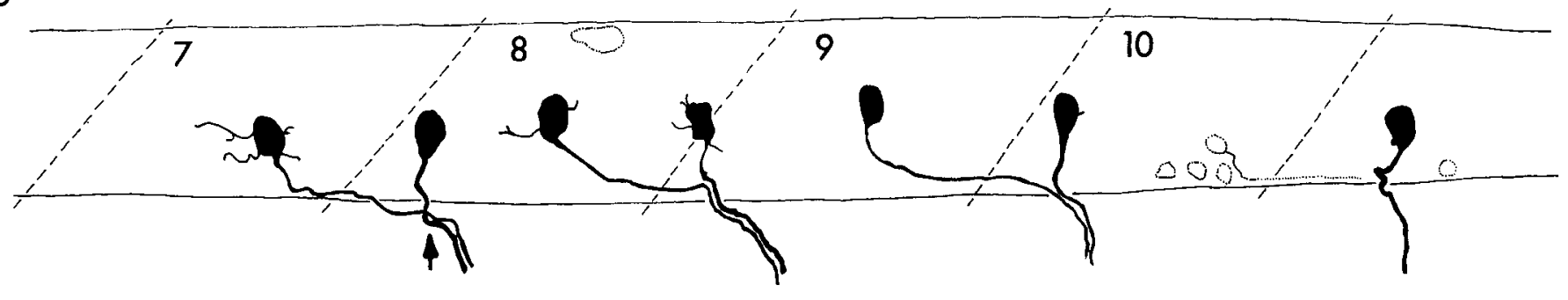

Figure 4. There are 3 types of primary motoneurons. Camera lucida drawings of HRP-labeled neurons from two 5-d-old animals $(A, B)$. The primary motoneurons are drawn in solid black, the other neurons that were labeled (secondary motoneurons and Rohon-Beard cells) are drawn as outlines. As in Figure 1, the plane is sagittal and rostral is at left. The solid horizontal lines mark the outlines of the spinal cord; the slanted dashed lines are the approximate locations of the myosepta. The numbers indicate segment number. Scale, $50 \mu \mathrm{m}$. $A$, MiP motoneurons. These cells were labeled by applying HRP to a longitudinal lesion of the dorsal median septum. MiP motoneurons are located approximately $20 \mu \mathrm{m}$ rostral to their ventral root, and only $1 \mathrm{MiP}$ motoneuron is labeled in each segment. $B, \mathrm{CaP}$ and RoP motoneurons. These cells were labeled with $\mathrm{HRP}$ applied to large lesions of the ventral musculature. A CaP motoneuron, which is located almost directly above each ventral root (arrow), can be found in 4 segments. A RoP motoneuron is located about $50 \mu \mathrm{m}$ rostrally (at left in the figure) from 3 of the ventral roots. The absence of the RoP motoneuron in segment $11 \mathrm{can}$ be ascribed to the normally observed variability of HRP uptake by these motoneurons; however, the unreliability of HRP uptake also makes it difficult to assess the amount of biological variation in motoneuron number.

toneurons in 13 animals). Direct observations with Nomarski optics demonstrated that in each animal, the CaP motoneurons of most trunk segments ( $68 \%$ of 38 segments in 4 animals) produce visible growth cones in the periphery within a span of $20 \mathrm{~min}$. The remaining $\mathrm{CaP}$ growth cones may appear significantly later, however, so that the observable period of axogenesis extends over an hour or more. Within a single animal, the most prolonged period of primary motor axogenesis was $3 \mathrm{hr}$ (from 18 to $21 \mathrm{hr}$ ).

No stereotyped sequence of development could be seen in the order of primary motor axogenesis. In Figure 7 is an example from a single animal with 6 labeled $\mathrm{CaP}$ motoneurons. The first trunk segments with CaP growth cones in the periphery were segments 14 and 15 , and the last was segment 7 . In other ani-

Figure 5. The 3 primary motoneurons have cell-specific positions within the spinal cord. The number of motoneurons found at a particular distance from the ventral root is plotted; distance rostral to the ventral root is to the left. All motoneurons labeled from lesions to the central muscles are represented by the solid dark bars, and the motoneurons labeled from lesions to the dorsal muscles by hatched bars. Top. Eighteen to $28 \mathrm{hr}$. The rostrocaudal positions of $60 \mathrm{CaP}$ and RoP motoneurons and $14 \mathrm{MiP}$ motoneurons labeled with fluorescent dyes were measured relative to the ventral root from the face of a video monitor. The $\mathrm{CaP}$ motoneurons are overrepresented in our sample. Overall, $65.7 \%$ of the labeled primary motoneurons were $\mathrm{CaP}$ motoneurons, $18.6 \%$ were $\mathrm{MiP}$ motoneurons, and $15.7 \%$ were RoP motoneurons. Bottom, Five days postfertilization. All measurements were taken from fixed HRP-labeled material. Three peaks in the distribution are apparent (at approximately 0,20 , and $40 \mu \mathrm{m}$ from the ventral root), although there is a degree of overlap in position of the motoneurons.
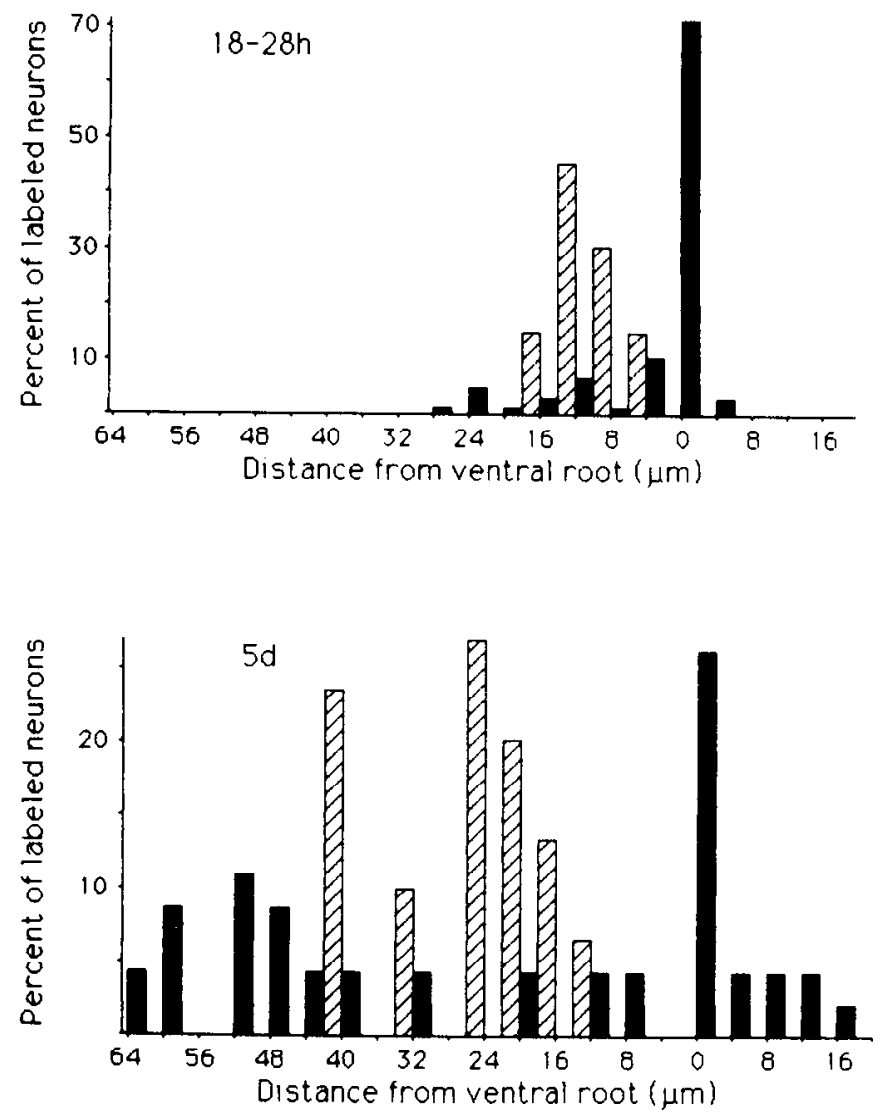

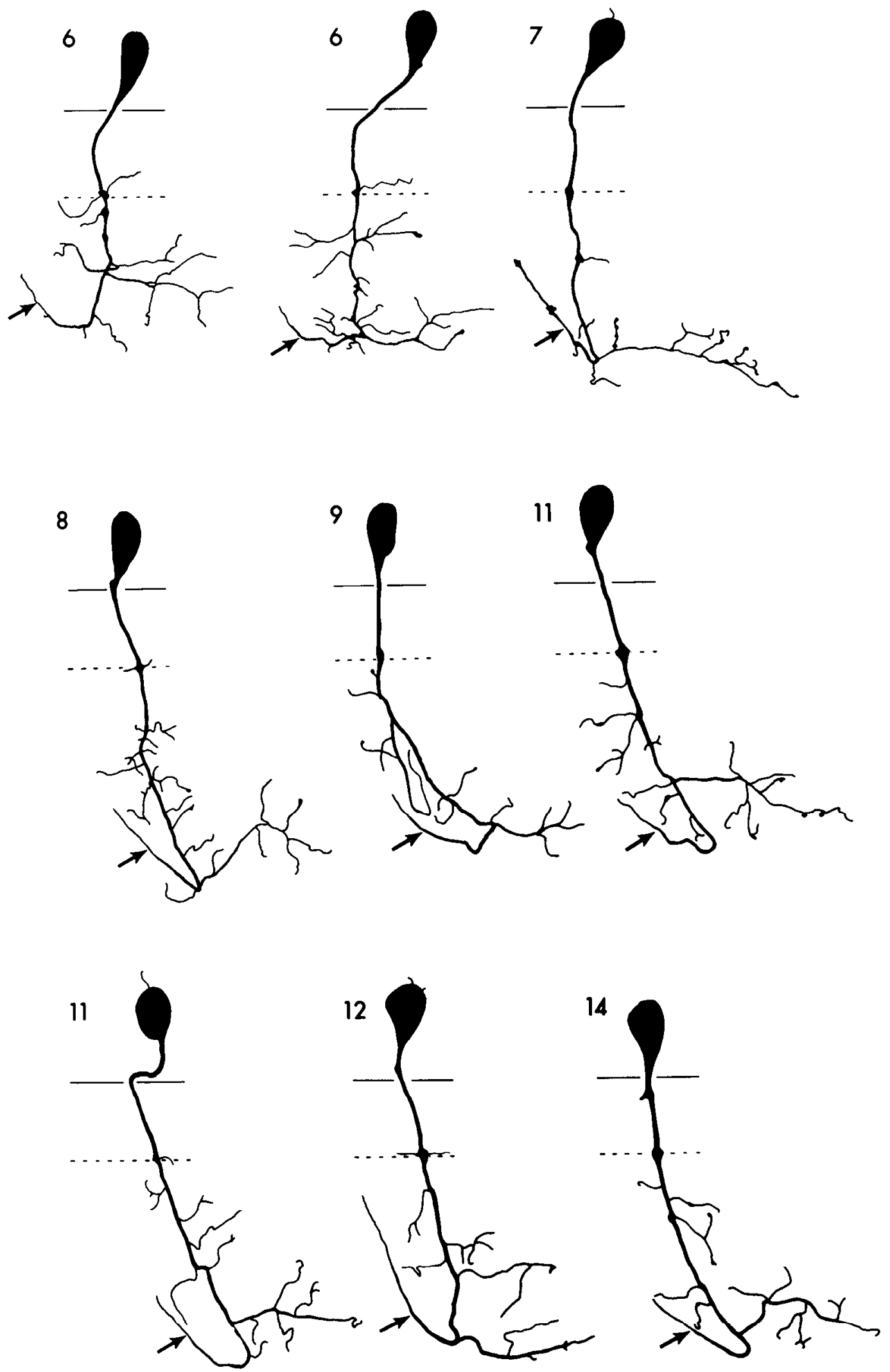

Figure 6. Specific features of primary motoneuron morphology are consistent from segment to segment and animal to animal. These 9 CaP motoneurons were drawn from 9 animals at $45-48 \mathrm{hr}$. The somata are located within a short distance of the ventral root, and the axons follow a stereotyped pathway down the middle of the segment, making a collateral or varicosity at the horizontal septum (dotted line). At the ventral edge of the musculature, each axon turns dorsally and laterally to grow along the rostral myoseptum (arrows). The numbers indicate the segment in which the cell was located. Scale, $50 \mu \mathrm{m}$. 
4

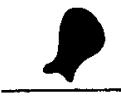

7
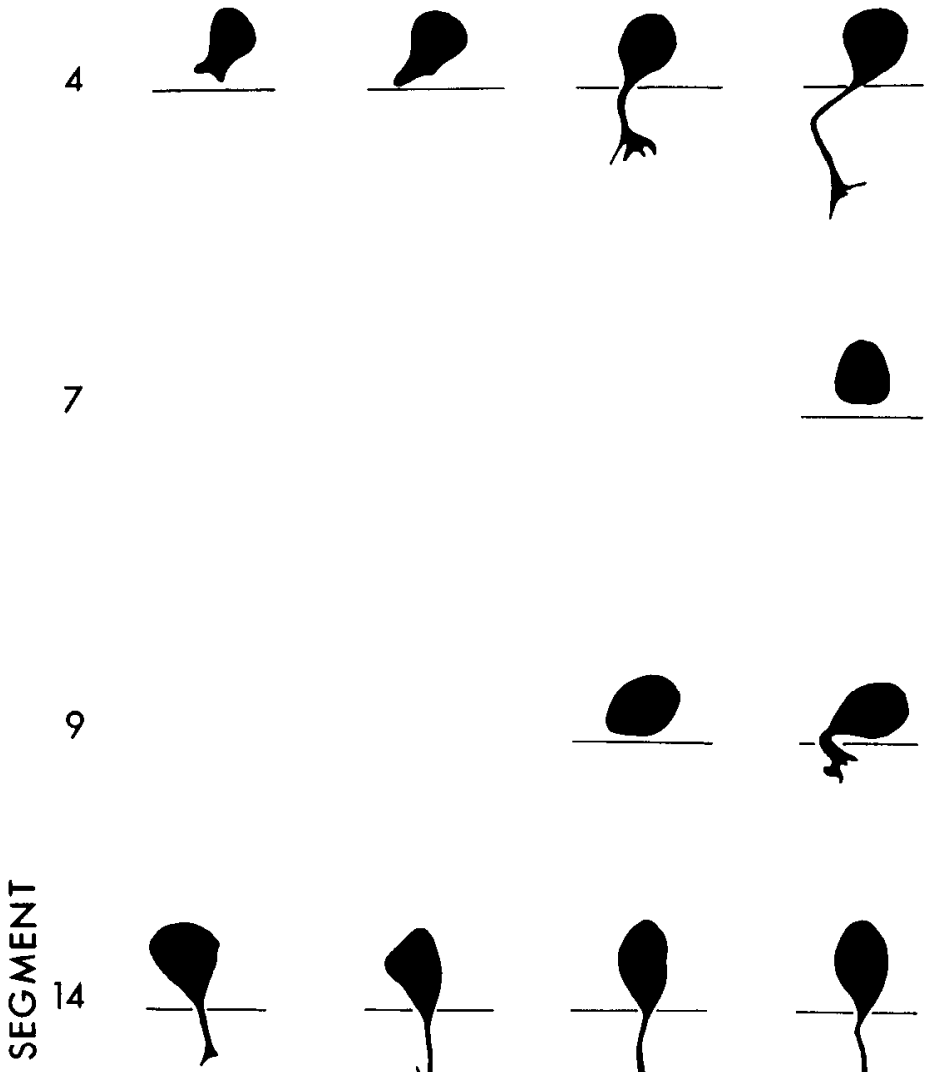

$15 \mathrm{~L}$
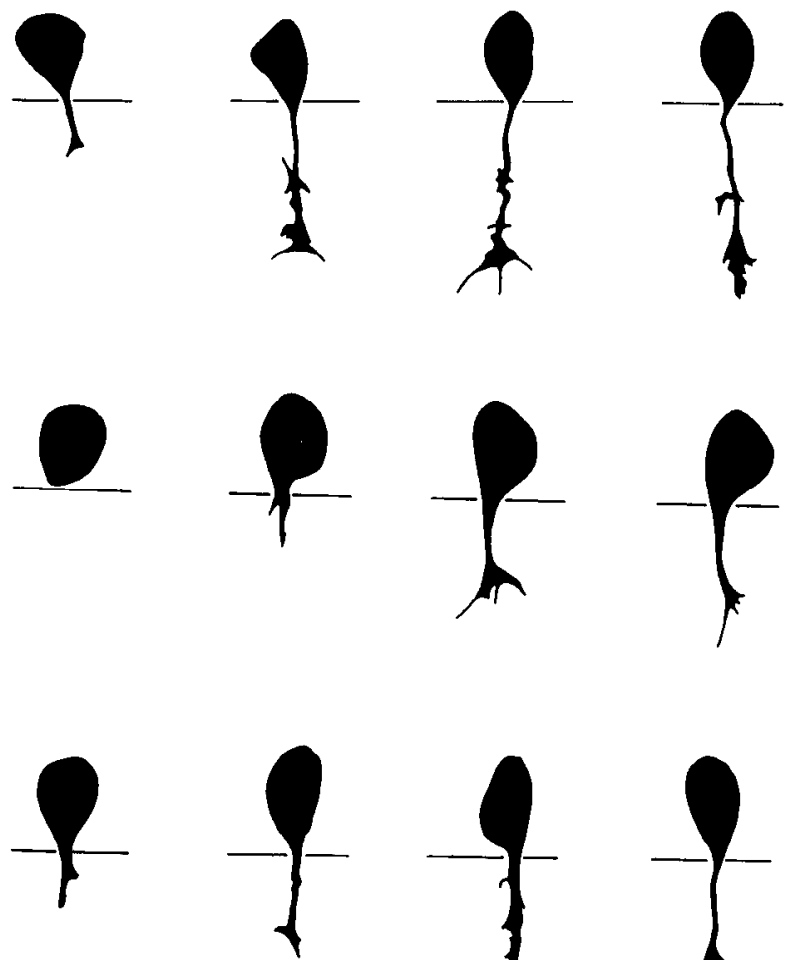

$15 \mathrm{R}$

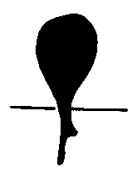

18
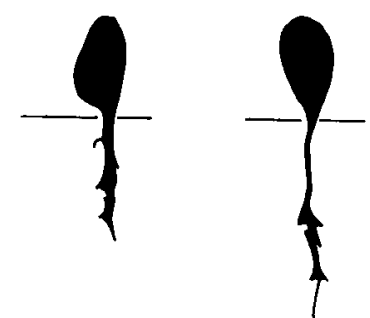

20

19.5
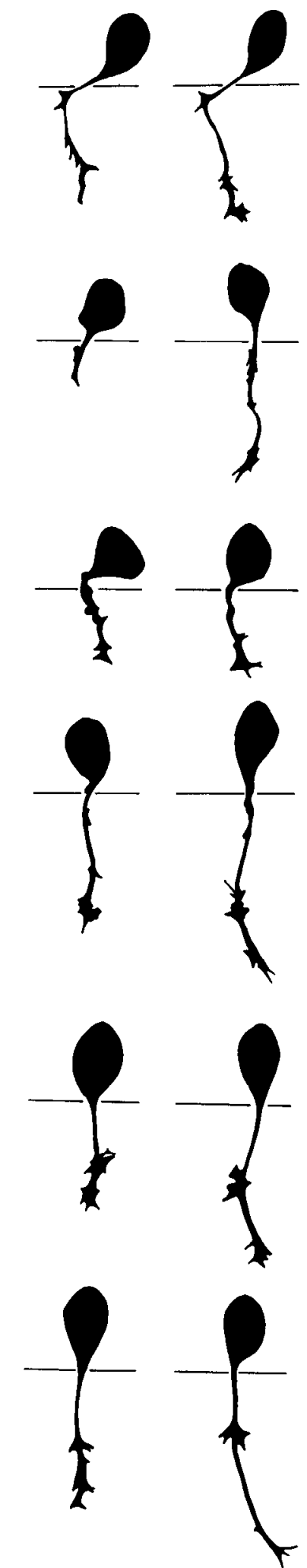

22

\section{AGE (hours)}

Figure 7. Motoneurons show no apparent synchrony or gradient of development. Drawings of fluorescently labeled CaP motoneurons from a single animal. These motoneurons were traced from the screen of a video monitor. Each horizontal row represents a single motoneuron at different times in its development. The age of the animal, in hours after fertilization, is indicated at the bottom of the drawing; the segment from which the motoneuron came is indicated to the left of each row. These 6 cells are all the labeled primary motoneurons from a single animal. Note that although all are of the same primary motoneuron type (CaP), individuals in different segments, or on opposite sides of the same segment (as shown in segments 15 left and 15 right), grow at different times. Scale, $50 \mu \mathrm{m}$. 


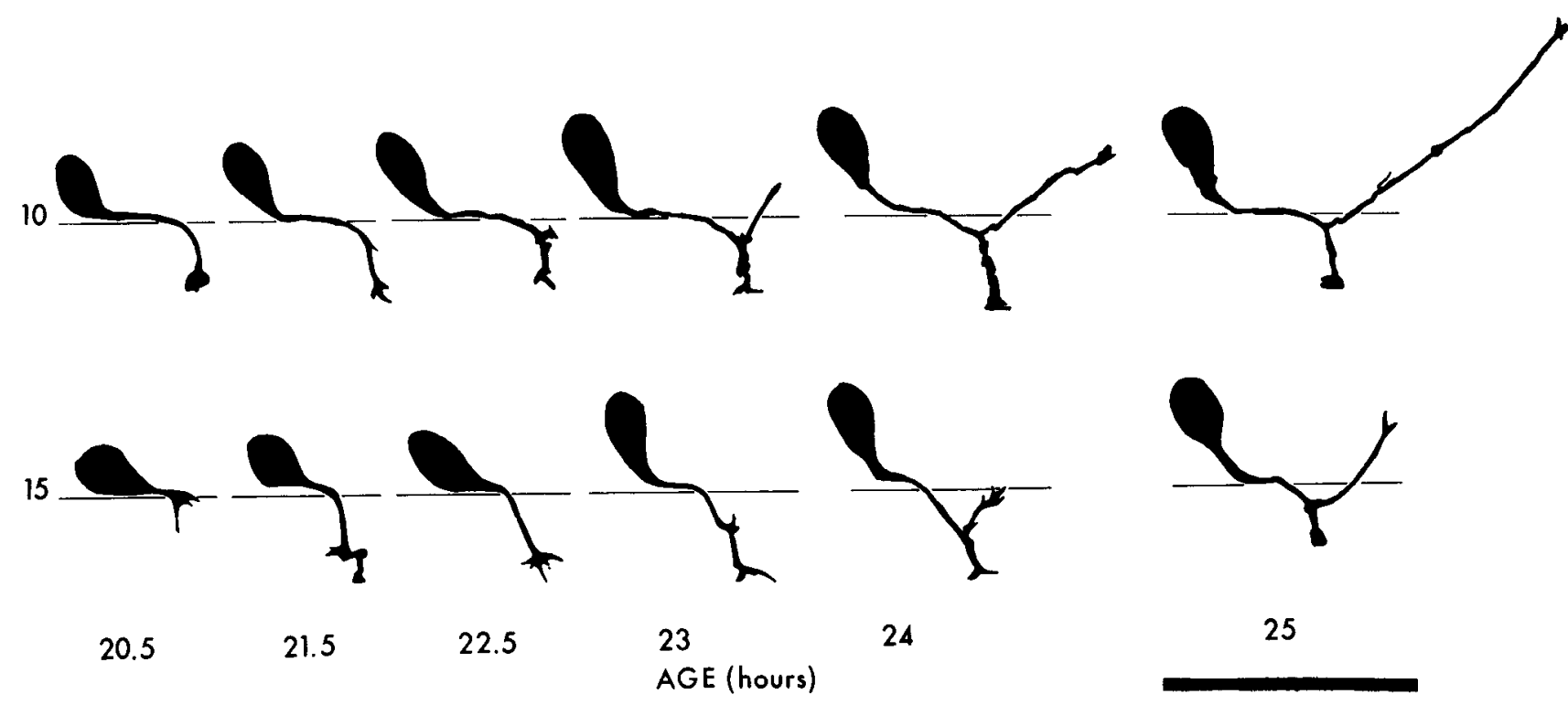

Figure 8. MiP motoneurons have growth cones that grow to the horizontal septum before their axons elaborate a dorsal collateral. Drawings of fluorescently labeled MiP motoneurons from a single animal. This drawing follows the conventions of Figure 7, with each row representing a single cell and time extending horizontally. Scale, $50 \mu \mathrm{m}$.

mals, different segments developed first and last, such that the sequence of $\mathrm{CaP}$ growth cone appearance was inconsistent from animal to animal. Our data show that within an individual animal there is no precisely predictable sequence of primary motor axon outgrowth. However, preliminary data based on the sequence of appearance of acetylcholinesterase in the zebrafish (Eric Hanneman, personal communication) suggest that rostral motoneurons tend to develop earlier than caudal motoneurons.

Axonal outgrowth is correlated with the first movements of the embryo. With Nomarski optics we were able to watch the emergence of the $\mathrm{CaP}$ growth cone from a segment and time the onset of muscle twitches in that same segment. In all cascs ( 7 animals), the appearance of the first motor growth cone in the periphery preceded the observation of the first twitches by no more than a few minutes. The twitches were confined to 1 or 2 muscle fibers, located on the inner surface of the muscle near the horizontal septum. Thesc fibers were distinguished by their smaller size and more advanced development as indicated by the presence of cross-striations (Eisen, Westerfield, and Huestis, unpublished observations; Felsenfeld, unpublished observations).

\section{Pathway selection and divergent choices by identified primary motor growth cones}

The growth cones of identified motoneurons followed a stereotyped sequence of development. CaP growth cones grew directly ventrally from the cell body and were often particularly large as they emerged from the spinal cord. They grew ventrally along the medial surface of the myotome, midway between the 2 segmental boundaries. As they grew, the growth cones diminished in size to a variable degree and become extensive again when they reached certain landmarks (see Fig. 7). The horizontal septum was a very consistent landmark (Eisen et al., 1986); growth cones of each type of primary motoneuron grew to the horizontal septum and then made divergent, cell-specific choices.

The $\mathrm{CaP}$ growth cones usually paused at the horizontal septum, sometimes for as long as $2 \mathrm{hr}$. After pausing, the CaP growth cone continued growing ventrally. In all but 2 cases out of 60 , the axon maintained a prominent varicosity at the septum long after the growth cone had passed. At the bottom of the notochord, the growth cones turned away from the notochord and entered the ventral median septum, and at the ventral end of the ventral median septum, the growth cone turned laterally and dorsally to grow superficially within the rostral myoseptum.

The growth cone of the primary motoneuron that innervates the dorsal muscle, MiP, grew ventrally at first (Fig. 8), following the same path as the CaP axon. On reaching the horizontal septum, howcver, the growth cone halted and the axon sprouted a dorsal collateral growth cone that grew dorsally between the surface of the spinal cord and the medial face of the axial muscle. In 3 cases, the initial ventral collateral of the MiP motoneuron was retracted simultaneously with the extension of the dorsal neurite. In other cases, as in Figure 8 , the collateral was maintained for as long as $20 \mathrm{hr}$. The collateral is eventually retracted; it has never been observed of HRP-labeled motoneurons in the larva.

The RoP motor growth cone followed a third pathway. Initially, it too followed the path to the horizontal septum pioneered by the $\mathrm{CaP}$ growth cone. After reaching the septum and typically pausing, it turned laterally and grew in the horizontal septum toward the lateral surface of the muscle. It later developed side branches that arborized in the muscle surrounding the horizontal septum.

These observations of pathfinding by growth cones were made in live embryos with fluorescently labeled motoneurons. A concern was that manipulation of the early embryo to inject the precursor cells or illumination of the dyes might disrupt normal development. To address this issue we compared the time course and pattern of axonal outgrowth of motoneurons that had been fluorescently labeled and observed in live embryos, with motoneurons acutely fixed and labeled with a monoclonal antibody, $\mathrm{zn}-\mathrm{l}$, which labels motoneurons and their axons (Trevarrow and Hanneman, 1985). An example of a CaP motoneuron stained with the zn-1 antibody is shown in Figure 9. The characteristic features of this neuron-specifically the position of its cell body, the prominent varicosity at the horizontal septum, and its axonal path-are typical of fluorescently labeled $\mathrm{CaP}$ motoneurons. This basic morphological pattern was observed without exception in 23 segments (6 animals) stained with the $\mathrm{zn}-1$ antibody at 23-24 hr. Moreover, zn-1 staining at earlier developmental times (20-22 hr, 3 animals) showed the segmental variability of $\mathrm{CaP}$ axonal outgrowth observed in fluorescently 

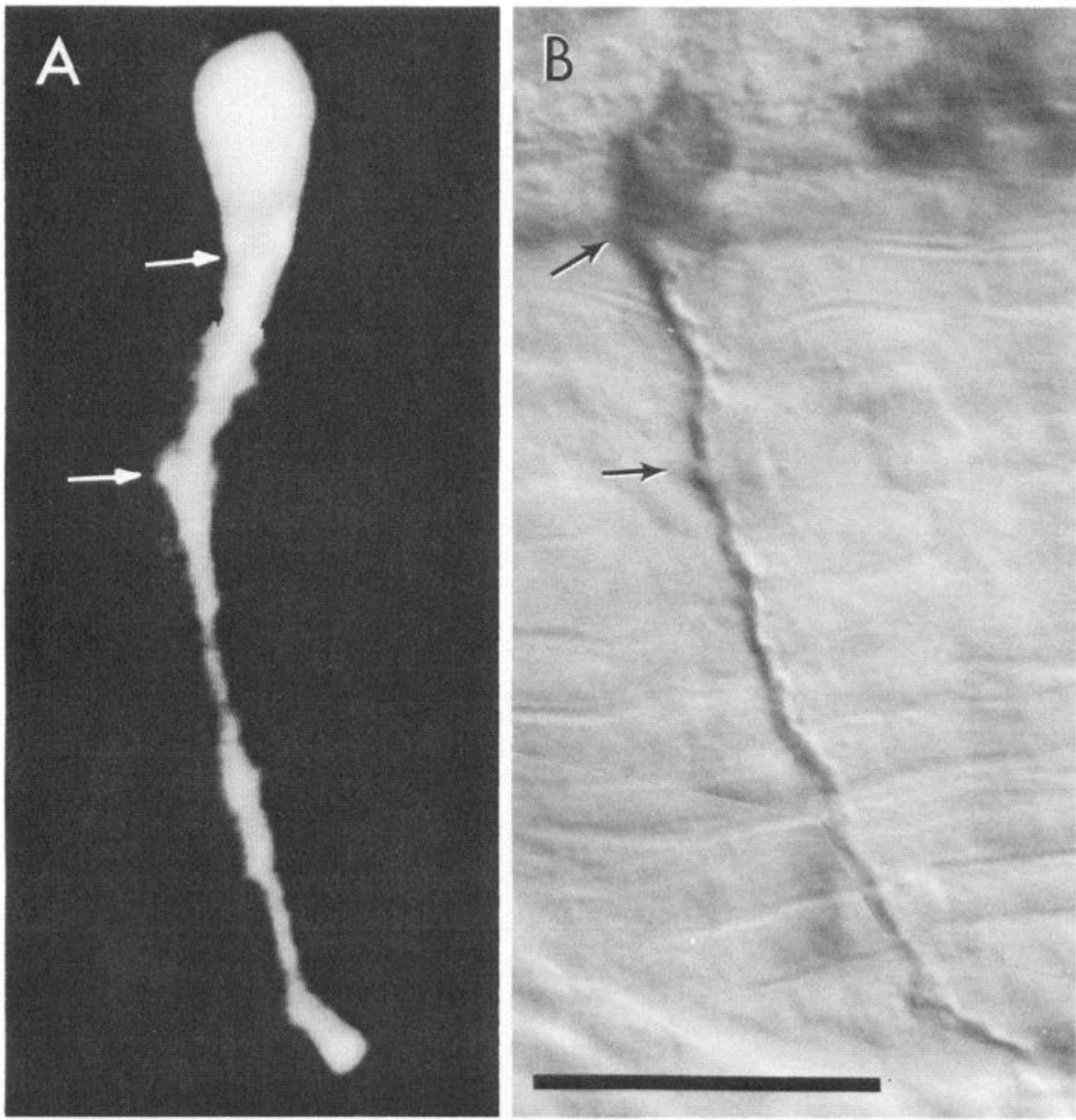

Figure 9. The morphology of chronically fluorescently labeled motoneurons appears the same as the morphology of unmanipulated motoneurons. Two $\mathrm{CaP}$ motoneurons from 2 different animals labeled with rhodamine-dextran $(A)$ and the monoclonal antibody zn-l $(B)$. The upper and lower arrows mark the location of the ventral root and horizontal septum, respectively. No significant differences in soma position, axon path, or the presence of common landmarks (such as the varicosity at the horizontal septum) have been found between chronically fluorescently labeled and acutely stained motoneurons. All differences between fluorescent and zn-l labeled motoneurons are well within the normal range of variation we have observed (see Fig. 6). Scale, $25 \mu \mathrm{m}$.

labeled preparations; it also revealed a tendency for more rostral motoneurons to be labeled earlier than more caudal motoneurons. In all cases, the pattern of $\mathrm{zn}-\mathrm{l}$ staining was consistent with our observations in live embryos.

Primary motor growth cones migrate through the periphery at the relatively slow average rate of $7.1 \pm 1.3 \mu \mathrm{m} / \mathrm{hr}$. The greatest burst of speed observed was the traversal of $24 \mu \mathrm{m}$ in $45 \mathrm{~min}$. We are confident that the slow rate of elongation of primary motor axons was not the result of photodamage or perturbation by our observations; labeled Rohon-Beard cells were seen together with primary motoneurons in 5 animals, and the growth cones of their ascending central axons migrated rostrally at the average rate of $103.3 \pm 8.1 \mu \mathrm{m} / \mathrm{hr}$, a rate similar to that reported for the descending axons of reticulospinal interneurons (Mendelson, 1985).

The peripheral arbors of primary motoneurons in the embryo are similar to those of primary motoneurons in the adult. Of 92 motoneurons in 30 animals, we observed only 1 clearly atypical primary motoneuronal projection; in no case, with the consistent exception of the MiP axon (described above), did we observe any remodeling of the peripheral arbor of a primary motoneuron, and in no case did we observe any consistent pattern of cell death.

\section{Axogenesis and pathfinding by secondary motoneurons}

Secondary motoneurons initiated axonal outgrowth later than primary motoneurons. Of the 13 animals that we studied to determine the time of primary motor axon outgrowth, all also contained labeled secondary motoneurons. The average age at which the first secondary motoneurons sent growth cones into the periphery was $26.4 \pm 1.7 \mathrm{hr}$, some $6 \mathrm{hr}$ after the primary motor growth cones. The shortest interval of time between the emergence of the latest primary motor growth cone $(23 \mathrm{hr})$ and the earliest secondary motor growth cone $(26 \mathrm{hr})$ within a single animal was $3 \mathrm{hr}$. New secondary motor growth cones continued to enter the periphery over an extended period of time; we observed 1 instance of a secondary motor growth cone emerging at some time after $34 \mathrm{hr}$. Sixty-eight percent ( 80 cases) of all secondary motor axons were added at some time after $29 \mathrm{hr}$.

The growth cones of secondary motoneurons were small and rounded (Fig. 3) or undistinguished except at the point where the axon ended. Secondary motor axons followed a path similar to that of the primary motor axons, but did not extend as far, and were never observed to make a loop and grow laterally over the surface of the muscle, as did the primary motor axons. Initially, the secondary motor growth cones grew along the medial surface of the axial muscles and made frequent collaterals that grew laterally into the muscle. It was not possible to determine whether the collaterals were branches from a single axon or individual axons separating from the main bundle. In the few cases where isolated secondary motoneurons were observed (for example, Fig. $1 \mathrm{C}$ ), secondary motor axons did branch significantly in the periphery, but to a lesser degree than did primary motor axons.

Although the secondary motoneurons were differentiating as the primary motoneuron somata migrated dorsally, secondary motoneuron somata did not similarly migrate. However, they did become dispersed longitudinally with time (Fig. 3). 


\section{Discussion}

\section{Role of the environment in motoneuron development}

Although these descriptive observations cannot directly demonstrate specific mechanisms, they strongly suggest that the primary motor growth cones are seeking and using cues in the environment as they grow to their targets. The horizontal septum and myosepta, in particular, are sites where such cues may reside. Primary motor growth cones have not been observed to cross the myosepta, although they grow along the myosepta. The growth cones of the RoP and $\mathrm{CaP}$ primary motoneurons often pause and make varicosities at the horizontal septum before following their cell-specific divergent pathways. The MiP motoneurons extend a neurite to the horizontal septum before making a dorsal process.

The slow, halting growth of the motor axons in the periphery itself suggests that motor growth cones are continually interacting with the environment. We have observed that the primary motor axons do not make any "mistakes" in pathway or target selection; their growth cones may be seeking out and following cell-specific guidance cues in the periphery.

The peripheral arbors of the primary motoneuronal types are unique and mutually exclusive (Westerfield et al., 1986). This pattern could arise either by specifically matching a primary motoneuron to its muscle targets or by some form of competitive exclusion between primary motoneurons during axon outgrowth. The latter model is complicated by the observation that both primary and secondary motor synapses coexist on a single muscle fiber into adulthood (Westerfield et al., 1986).

\section{Role of timing in the development of primary and} secondary motoneurons

The differences between primary and secondary motoneurons are established before the embryo is $24 \mathrm{hr}$ old. Primary motoneurons are born approximately $6 \mathrm{hr}$ before secondary motoneurons. At the earliest ages that we can identify the cells, the average primary motoneuron is roughly twice the size of the average secondary motoneuron. As in other organisms (Jacobson, 1978), neuron size and time of origin are correlated.

Mendelson (1985) has shown that the dorsal position of interneurons in the hindbrain of the zebrafish is correlated with their time of origin. He has suggested that interneurons that are born early come to occupy more dorsal positions because they are passively shifted by the addition of later cells and axons to the ventral floor of the hindbrain. We have also found a clear correlation between the time of origin of spinal motoneurons and their dorsal position within the spinal cord; however, the mechanism may be different. Primary motoneurons are first observed on the ventral floor of the spinal cord but then appear to migrate actively to their final location. The dorsal migration of the somata may be a feature unique to primary motoneurons and, even more specifically, unique to teleost motoneurons, since it has not been described for amphibians (Blight, 1978; Roberts and Clarke, 1982).

A significant functional difference between primary and secondary motoneurons is indicated by the observation of contacts from the Mauthner axon exclusively on the primary motor neurites (Myers, 1985). Mendelson (1985) described the timing of Mauthner axon growth in the zebrafish. The Mauthner axon growth cone first reaches the fifth segment of the spinal cord at $21 \mathrm{hr}$; it grows along the ventral floor of the spinal cord at 100 $\mu \mathrm{m} / \mathrm{hr}$ and reaches the level of the 15 th segment at approximately $26 \mathrm{hr}$. The Mauthner axon is actively growing within the spinal segments we have studied after the primary motoneurons have initiated axonal outgrowth and before the secondary motoneurons have begun axonal outgrowth. The sequence of primary motor axonal outgrowth, Mauthner axonal outgrowth, and secondary motor axonal outgrowth suggests a basis for selective synapse formation by the Mauthner axon; at the time the Mauthner growth cone grows through the trunk region of the spinal cord, only the primary motoneurons have elaborated axons that are, presumably, available to receive synaptic contacts. The later-growing secondary motor axons are then unable to receive contacts from the Mauthner axon growth cone. We have not, however, performed any conclusive experiments to demonstrate the dependence of Mauthner axon specificity on the precise timing of outgrowth.

It is unclear whether timing plays a significant role in determining the differences among the 3 types of primary motoneurons-CaP, MiP, and RoP. Within an animal and in different segments, we cannot find any consistent difference in either the time of origin or the time of initial axonal outgrowth of these 3 cell types. Within a single segment, however, the $\mathrm{CaP}$ growth cone invariably leaves the spinal cord before the growth cones of the other 2 primary motoneurons. The difference in time is small, and may be due simply to the greater distance the MiP and RoP growth cones must grow before reaching the ventral root, since our evidence suggests that all the primary motoneurons within a segment initiate axonal outgrowth within a short time of one another. This small but consistent timing difference may be significant and could give $\mathrm{CaP}$ an advantage in "capturing" the ventral muscles. Alternatively, motoneuron type might be an intrinsic property, specified by such factors as soma position or cellular lineage.

The nearly simultaneous differentiation of the primary motoneurons within each side of a segment also suggests the interesting possibility that individual spinal segments in the zebrafish are discrete developmental compartments that carry out a specific sequence of development independently of other spinal segments. The primary motoneurons of each segment are spatially discrete from those of other segments, and their peripheral arbors in the embryo and larva are restricted to a single side and do not cross segmental borders; this spatial segregation may be a result of a developmental process that partitions the spinal hemisegments into isolated, autonomously differentiating units.

\section{References}

Ball, E. E., R. K. Ho, and C. S. Goodman (1985) Development of neuromuscular specificity in the grasshopper embryo: Guidance of motoneuron growth cones by muscle pioneers. J. Neurosci. 5: 18081819.

Blight, A. R. (1978) Golgi staining of "primary" and "secondary" motoneurons in the developing spinal cord of an amphibian. J. Comp. Neurol. 180: 679-690.

Eiscn, J. S., P. Z. Myers, and M. Westerfield (1984) Segmentally specific growth of motor axons in live zebrafish embryos. Soc. Neurosci. Abstr. 10: 371 .

Eisen, J. S., P. Z. Myers, and M. Westerfield (1985) Functional interactions between identified growth cones and muscles in embryonic zebrafish. Soc. Neurosci. Abstr. 11: 586.

Eisen, J. S., P. Z. Myers, and M. Westerfield (1986) Pathway selection by growth cones of identified motoneurons in live zebrafish embryos. Nature 320: 269-271.

Farel, P. B., and S. E. Bemelmans (1985) Specificity of motoneuron projection patterns during development of the bullfrog tadpole (Rana catesheiana). J. Comp. Neurol. 238: 128-134.

Hisaoka, K. K., and H. I. Battle (1958) The normal developmental stages of the zebrafish, Brachydanio rerio (Hamilton-Buchanan). J. Morphol. 102(2): 311-328.

Hollyday, M. (1980) Of motor pools in the chick lumbar lateral motor column. J. Comp. Neurol. 194: 143-170.

Hollyday, M. (1983) Development of motor innervation of chick limbs. In Limb Development and Regeneration, pp. 183-193, Liss, New York.

Jacobson, M. (1978) Developmental Neurobiology, pp. 103-111, Plenum, New York. 
Kater, S. B., and R. D. Hadley (1982) Intracellular staining combined with video fluorescence microscopy for viewing living identified neurons. In Cytochemical Methods in Neuroanatomy, pp. 441-459, Liss, New York.

Kimmel, C. B., and R. D. Law (1985) Cell lineage of zebrafish blastomeres. Dev. Biol. 108: 78-101.

Lamb, A. H. (1976) The projection patterns of the ventral horn to the hind limb during development. Dev. Biol. 54: 82-99.

Lamb, A. H. (1977) Neuronal death in the development of the somatotopic projections of the ventral horn in Xenopus. Brain Res. 134 145-150.

Lamb, A. H. (1979) Evidence that some developing limb motoneurones die for reasons other than peripheral competition. Dev. Biol. 71: 8-21.

Lance-Jones, C., and L. Landmesser (1980a) Motoneurone projection patterns in embryonic chick limbs following partial deletions of the spinal cord. J. Physiol. (Lond.) 302: 559-580.

Lance-Jones, C., and L. Landmesser (1980b) Motoneuron projection patterns in the chick hindlimb following early partial spinal cord reversals. J. Physiol. (Lond.) 302: 581-602.

Lance-Jones, C., and L. Landmesser (1981a) Pathway selection by chick lumbosacral motoneurones during normal development. Proc. R. Soc. London [Biol.] 214: 1-18.

Lance-Jones, C., and L. Landmesser (1981b) Pathway selection by embryonic chick motoneurons in an experimentally altered environment. Proc. R. Soc. London [Biol.] 214: 19-52.

Landmesser, L. T. (1980) The generation of neuromuscular specificity. Annu. Rev. Neurosci. 3: 279-302.
Landmesser, L., M. J. O'Donovan, and M. Honig (1983) The response of avian hindlimb motor and sensory neurons to an altered periphery. In Limb Development and Regeneration, pp. 207-216, Liss, New York.

McGrath, P. A., and M. R. Bennett (1979) The development of synaptic connections between different segmental motoneurones and striated muscles in axolotl limb. Dev. Biol. 69: 133-145.

Mendelson, B. (1985) Soma position is correlated with time of development in three types of identified reticulospinal neurons. Dev. Biol. 112: 489-493.

Miller, J. P., and A. I. Selverston (1979) Rapid killing of single neurons by irradiation of intracellularly injected dye. Science 206: 702-704.

Myers, P. Z. (1985) Spinal motoneurons of the larval zebrafish. J. Comp. Neurol. 237: 555-561.

Pettigrew, A., R. Lindeman, and M. R. Bennett (1979) Development of segmental innervation of the chick forelimb. J. Embryol. Exp. Morphol. 49: 115-137.

Roberts, A., and J. D. W. Clark (1982) The neuroanatomy of an amphibian eribryo spinal cord. Philos. Trans. R. Soc. London, Ser. B 296: 195-212.

Trevarrow, B., and E. Hanneman (1985) Segmental patterns of development in the zebrafish CNS. Soc. Neurosci. Abstr. 11: 604.

Westerfield, M., J. McMurray, and J. S. Eisen (1986) Identified motoneurons and their innervation of axial muscles in the zebrafish. J. Neurosci. 6: 2267-2277. 